Erratum

\title{
Erratum: Panagopoulos, C.N., et al. Wear Behaviour of Nanostructured Polymer-Based Safety Films on Soda-Lime Glass. Coatings 2016, 6, 26
}

\author{
C. N. Panagopoulos ${ }^{1, *}$, E. P. Georgiou ${ }^{2,3}$, G. S. Tradas ${ }^{1}$ and K. I. Giannakopoulos ${ }^{1,+}$
}

1 Laboratory of Physical Metallurgy, National Technical University of Athens, Zografos, 15780 Athens, Greece; geotra5@yahoo.gr (G.S.T.); kgiannakopoulos@puas.gr (K.I.G.)

2 Department of Materials Engineering (MTM), Katholieke Universiteit Leuven (K.U. Leuven),

Kasteelpark Arenberg 44, B-3001 Leuven, Belgium; emmanuel.georgiou@mtm.kuleuven.be

3 Falex Tribology NV, Wingepark 23B, 3110 Rotselaar, Belgium

* Correspondence: chpanag@metal.ntua.gr; Tel.: +30-210-7722171

+ Present address: Laboratory of Strength of Materials, Department of Mechanical Engineering, Piraeus University of Applied Sciences (Technological Educational Institute of Piraeus), 12244 Egaleo, Athens, Greece.

Received: 1 December 2016; Accepted: 1 December 2016; Published: 14 December 2016

The authors wish to make the following change to their paper [1].

Co-author, K. I. Gianakopoulos' name should be replaced with K. I. Giannakopoulos.

The authors apologize for any inconvenience this may cause.

The change does not affect the scientific results. The manuscript will be updated and the original will remain online on the article webpage.

\section{Reference}

1. Panagopoulos, C.N.; Georgiou, E.P.; Tradas, G.S.; Giannakopoulos, K.I. Wear Behaviour of Nanostructured Polymer-Based Safety Films on Soda-Lime Glass. Coatings 2016, 6, 26. [CrossRef]

(C) 2016 by the authors; licensee MDPI, Basel, Switzerland. This article is an open access article distributed under the terms and conditions of the Creative Commons Attribution (CC-BY) license (http:/ / creativecommons.org/licenses/by/4.0/). 